\title{
Microbial Degradation of Reactive Orange M2R Dye by an Application of Bacterial Consortium ETL-A: Bioremedial Approach towards Sustainable Environment
}

\author{
Shah M \\ Industrial Waste Water Research Laboratory \\ Division of Applied \& Environmental Microbiology Lab, \\ India.
}

\begin{abstract}
Textile and Textile dyestuff industries discharge effluent having high Chemical Oxygen Demand $(C O D)$ and colour, making it difficult to treat the effluent completely. Several Physical, Chemical and Biological treatment methods are available to treat such an effluent. However, in recent years biological treatment with focus on bacteria have been drawing a tremendous attention due to their ability to degrade complex structured dyes and hence treat waste water. In the present study, Soil and Water samples collected from textile dye effluent contaminated sites of Ankleshwar, Gujarat was studied for screening and isolation of bacteria capable of decolorizing and degrading textile dyes. A bacterial consortium ETL-A was selected on the basis of rapid dye decolorization. Bacterial consortium exhibited 93\% decolorization ability within 30 hours under static conditions at $35^{\circ} \mathrm{C}$ in presence of Glucose and Yeast Extract as cosubstrates. 16S rRNA gene amplification was carried out for the sequencing and identification of these strains. The degradation of dye was confirmed by HPTLC and FTIR analysis. Considerable decrease in COD of the dye (above $85 \%$ ) was indicative of conversion of complex dye into simple oxidizable products.
\end{abstract}

Keywords: Reactive orange M2R, Biodegradation, HPTLC, FTIR, COD, ETL-A.

\section{INTRODUCTION}

Worldwide, dye wastewater has become one of the main sources of severe pollution problems due to the greater demand for textile products and the proportional increase in production and applications of synthetic dyes [Santos et al., 2007]. It is estimated that over 10,000 different dyes and pigments are used industrially and over 0.7 million tons of synthetic dyes are produced annually worldwide [Robinson et al., 2001]. In the textile industry, up to 200,000 tons of these dyes are lost to effluents every year during dyeing and finishing operations as a result of inefficiency in the dyeing process [Zollingar et al., 1987, Ji et al., 2008]. Unfortunately, most of these dyes escape conventional wastewater treatment processes and persist in the environment as a result of their high stability against light, temperature, water, detergents, chemicals, and microbial attack [Couto., 2009]. Notwithstanding, industries are required to eliminate color from their effluents containing dyes, before disposal into water bodies, due to environmental legislation [Neil et al., 1999]. Several reports have also shown that textile dyes and effluents have toxic effects on plants which perform important ecological functions such as providing a habitat for wildlife, protecting soil from erosion, and providing the organic matter that is so significant to soil fertility [Ghodake et al., 2009]. Consequently, it is pertinent to develop efficient treatment strategies for removal of color from dye wastewater. Various physicochemical methods, such as adsorption on activated carbon, electro coagulation, flocculation, froth flotation, ion exchange, membrane filtration, ozonation, and reverse osmosis have been used for decolorization of dyes in wastewater [Robinson et al., 2001, Gupta et al., 2004]. However, these methods are less efficient, costly, of limited applicability, and produce wastes, which are difficult to dispose of [Daneshwar et al., 2007]. On the contrary, biological processes provide a low-cost, environmentally benign, and efficient alternative for the treatment of dye wastewater [Ali et al., 2009]. Decolorization by biological means may take place in two ways: either by adsorption (or biosorption) on the microbial biomass or biodegradation by the cells [Zhou et al., 1993]. Biosorption involves the entrapment of dyes in the matrix of the adsorbent (microbial biomass) without destruction of the pollutant, whereas in biodegradation, the original dye structure is 
fragmented into smaller compounds resulting in the decolorization of synthetic dyes. Several researchers have described the use of microorganisms as biosorption agents in the removal of pollutants from wastewater [Gupta \& Rastogi., 2008, 2009, Won et al., 2005]. However, due to operational ease and facile adaptability of microorganisms to a given set of conditions, the biodegradation mechanism is considered efficacious in comparison to biosorption for treatment of dye wastewater [Singh \& Arora., 2011]. Over the past few decades, numerous microorganisms have been isolated and characterized for degradation of various synthetic dyes, but most of the reports have dealt mainly with decolorization of azo dyes [Tony et al., 2009, Gou et al., 2009, Telke et al., 2008]. In the present study, a consortium was selected from four consortiums isolated from soil and water samples collected from areas of textile dyeing and printing in Ankleshwar, Gujarat, India and its ability to degrade Reactive Orange M2R (ROM2R) a monoazo dye was analyzed. The consortium's ability to remove Chemical oxygen demand was measured to ensure the ability of the consortium to convert complex dye to simple non toxic compound. The degraded product after the treatment with consortium ETL-A was analyzed by HPTLC and FTIR.

\section{MATERIALS AND MethodS}

\section{Chemicals \& Dyes}

The textile dyes that are manufactured and used mostly for dyeing and printing were selected for the study. The common name of all dyes has been used for convenience; the dyes were procured from local textile industry, Ankleshwar, Gujarat, India. The dyes were Remazol Brilliant Red 5, Reactive Orange M2R, Reactive Red 195, Red HE8B, Reactive Blue 59, Remazol Brilliant Blue R, Remazol Black B, Reactive Black 8. A monoazo dye Reactive Orange M2R (ROM2R) was selected as model dye for all experiments.

\section{Growth Medium}

Bushnell and Haas medium (BHM) (HiMedia) containing the following in gl-1: MgSO4, 0.2; K2HPO4, 1.0; $\mathrm{CaCl} 2,0.02 ; \mathrm{FeCl} 3,0.05 ; \mathrm{NH} 4 \mathrm{NO} 3,1.0$ supplemented with Glucose $(0.1 \%$ w/v), Yeast extract $(0.3 \% \mathrm{w} / \mathrm{v})$ and $100 \mathrm{ppm}(\mathrm{mgl}-1)$ ROM2R was used for enrichment of organisms in soil and water sample.

\section{Sample Collection}

Soil and water samples were collected from areas of textile dyeing and printing in Ankleshwar, Gujarat, India was used for screening of dye decolorizing bacteria.

\section{Enrichment of Dye Degrading Organisms}

BHM media containing dye (ROM2R $100 \mathrm{mgl}-1$ ) as sole source of carbon and energy (without cosubstrate) $(100 \mathrm{ml})$ was taken in $250 \mathrm{ml}$ Erlenmeyer flasks and was inoculated with $10 \mathrm{ml}$ of soil suspension $(10 \% \mathrm{w} / \mathrm{v})$ and incubated under static condition at $37^{\circ} \mathrm{C}$. Repeated transfers were carried out in fresh dye containing media till stable dye decolorizing cultures were obtained showing consistent growth and decolorization during successive transfer. Same was repeated for water samples. Co-substrates such as glucose and Yeast Extract were also used along with dye in BHM media.

\section{Identification by Gram Staining and 16SrRNA}

The cultures that showed consistent decolorization were subjected to separation on dye containing agar plates and were submitted to Bangalore Genei, Bangalore, India for identification by $16 \mathrm{~S}$ rRNA sequencing method.

\section{COD Reduction during Decolorization}

The decolorization medium was observed for the change in Chemical Oxygen Demand at different time intervals. For determining change in COD, titrimetric procedure was followed in which supernatant refluxed with potassium dichromate, in presence of silver sulfate, mercury sulfate and concentrated $\mathrm{H}_{2} \mathrm{SO}_{4}$ was titrated with Ferrous Ammonium Sulfate (FAS) using ferroin indicator (APHA, 2005).

\section{Dye Decolorization under Static and Shaking Conditions}

Bushnell and Haas Broth (BHB) $100 \mathrm{ml}$ in $250 \mathrm{ml}$ Erlenmeyer flasks along with glucose $(0.1 \% \mathrm{w} / \mathrm{v})$ and Yeast Extract $(0.3 \% \mathrm{w} / \mathrm{v})$ amended with $100 \mathrm{ppm}$ of ROM2R was inoculated with bacterial culture $(5 \% \mathrm{w} / \mathrm{v})$ and incubated at $37^{\circ} \mathrm{C}$ under static or shaking conditions. All the decolorization experiments were performed in triplicates. 
Microbial Degradation of Reactive Orange M2R Dye by an Application of Bacterial Consortium ETL-A: Bioremedial Approach towards Sustainable Environment

\section{Analysis of Growth and Decolorization of ROM2R}

Culture broth of $5 \mathrm{ml}$ was collected from each flask at different time intervals of incubation. These samples were centrifuged at $8000 \mathrm{rpm}$ for 10 minutes and supernatant was analysed by UV-Vis spectrophotometer (Shimadzu UV-1800, Japan) at $\lambda \max$ of respective dye ( $\lambda$ max of $\mathrm{ROM} 2 \mathrm{R}=488 \mathrm{~nm}$ ). The cell pellet obtained upon centrifugation of $5 \mathrm{ml}$ culture was resuspended in 5 $\mathrm{ml}$ distilled water and its absorbance was studied at $660 \mathrm{~nm}$. The uninoculated flask containing the dye (ROM2R) was used as reference to correct the abiotic colour disappearance and the uninoculated medium without dye was used as blank. The efficiency of dye decolorization was determined based on the reduction of the absorbance in relation to the zero time absorbance expressed as percentage. The decolorization efficiency was expressed as follows:

$\%$ decolorization $=[(\mathrm{Ai}-\mathrm{Af}) / \mathrm{Ai}] \times 100$

Where Ai = Initial Absorbance,

Af $=$ Final Absorbance

\section{HPTLC Analysis of the Degraded Product}

Degradation of dyes was monitored on precoated TLC silica gel plates. The culture supernatants at different periods during decolorization were used for analysis. A $10 \mu 1$ of the sample was spotted on TLC plates using a micro syringe. The solvent system used was n-propanol, methyl ethyl ketone, Ammonium hydroxide $(4: 3: 3 \mathrm{v} / \mathrm{v})$. The dye chromatogram was observed in day light and in UV light (254nm).

\section{Fourier Transform Infra Red Spectroscopy Analysis of Degraded Product}

Metabolites produced by biodegradation of the ROM2R were extracted with equal volumes of ethyl acetate. The extracts were dried over anhydrous $\mathrm{Na} 2 \mathrm{SO}_{4}$ evaporated to dryness in rotary evaporator and analysed. FTIR analysis was carried out on Thermo Scientific 6700 set up, frequency range $4000 \mathrm{~cm}-1$ to $400 \mathrm{~cm}-1$.

\section{Spectrum of Dyes Decolorized by the Culture}

Mixture of various dyes is present in industrial effluents therefore ability of the consortium VSS to decolorize different dyes was studied.

\section{ReSults AND Discussions}

\section{Screening pattern of Dye Decolorizing Bacterial Cultures}

Isolation of bacteria was carried out from textile dye contaminated soil and water samples from various sites of Ankleshwar GIDC, Gujarat, India for decolorization and degradation of textile dyes. Four different bacterial consortium namely ETL-A, ETL-B, ETL-C, ETL-4 were isolated by enrichment culture technique using dye ROM2R (100 ppm) and also by adding glucose and Yeast Extract as co-substrates. It was evident from the results that addition of co-substrate is essential for decolorization. The same was reported by (Nigam et al, 1996). Of all the bacterial consortia obtained, bacterial consortium ETL-A was found to be the most efficient with maximum decolorization efficiency under static conditions at $37{ }^{\circ} \mathrm{C}$. Four different bacterial species were obtained upon isolation on dye agar plates from the mixed consortium ETL-A. When each pure culture was tested individually for its decolorizing ability in liquid medium and in combination with other pure cultures, none of the cultures showed decolorization even on extended incubation. But, when all the four bacterial cultures were mixed and inoculated together in a liquid medium, complete decolorization of ROM2R was observed, thus suggesting role of all four bacterial species in decolorization. Chen et al, 2006, Bafana et al, 2007, Yang et al, 2009, Patil et al, 2010, Phugare et al, 2011 reported synchronized action of microorganisms for the biodegradation of textile dye.

\section{Change in COD during Decolorization}

All four bacterial consortia isolated by enrichment culture technique were studied for change in COD. Mixed results were obtained with different consortia. Consortium ETL-D showed minimum COD reduction of $38 \%$ and $60 \%$ of ROM2R dye in 24 hours and 48 hours of inoculation respectively. Consortium ETL-A showed maximum COD reduction of $67 \%$ and $83 \%$ of ROM2R dye in 24 hours and 48 hours of inoculation respectively. All the other consortia showed COD reductions in between the COD reduction by ETL-D and ETL-A (Figure 1). High rate in COD reduction is considered as an indicator of mineralization. (Hassan et al, 2002). 


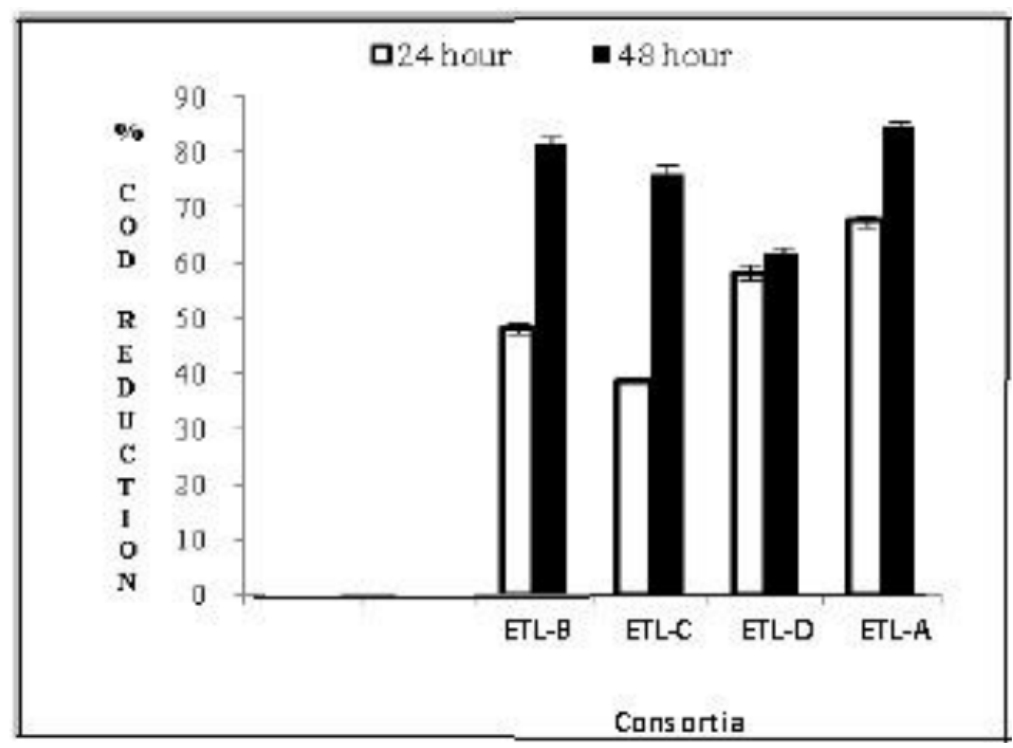

Fig 1. Reduction in $C O D$

\section{Identification of Cultures Present in Consortium VSS by Gram Staining and 16S rRNA Technique}

ETL-A consortium obtained after enrichment culture technique was subjected to gram staining. Organism present in consortium ETL-A was identified by 16SrRNA technique. The consortium contains Bacillus subtilis, Stenotrophomonas sp., Pseudomonas stutzeri and Pseudomonas aeruginosa

\section{Decolorization Ability and Growth Pattern of Consortium ETL-A under Static/Shaking Conditions}

Decolorization ability and growth of the bacterial cultures under static/shaking conditions was obtained by spectrophotometric method and the results are represented in Figure 2 and 3. The consortium ETL-A exhibited decolorization up to $93 \%$ within 30 hours under static condition, whereas under shaking condition, the culture showed $20 \%$ decolorization of ROM2R dye in 30 hours. Under shaking condition, the culture though showed faster growth, it showed lesser decolorization. The results clearly indicated that decolorization was not depended on biomass concentration but was significantly correlated with dissolved oxygen. The azo reductase driven bacterial decolorization of azo dyes is normally inhibited by the presence of oxygen primarily due to competition in oxidation of reduced electron carriers (e.g. NADH) with either Oxygen or Azo group as the electron receptor (Chang et al, 2000).

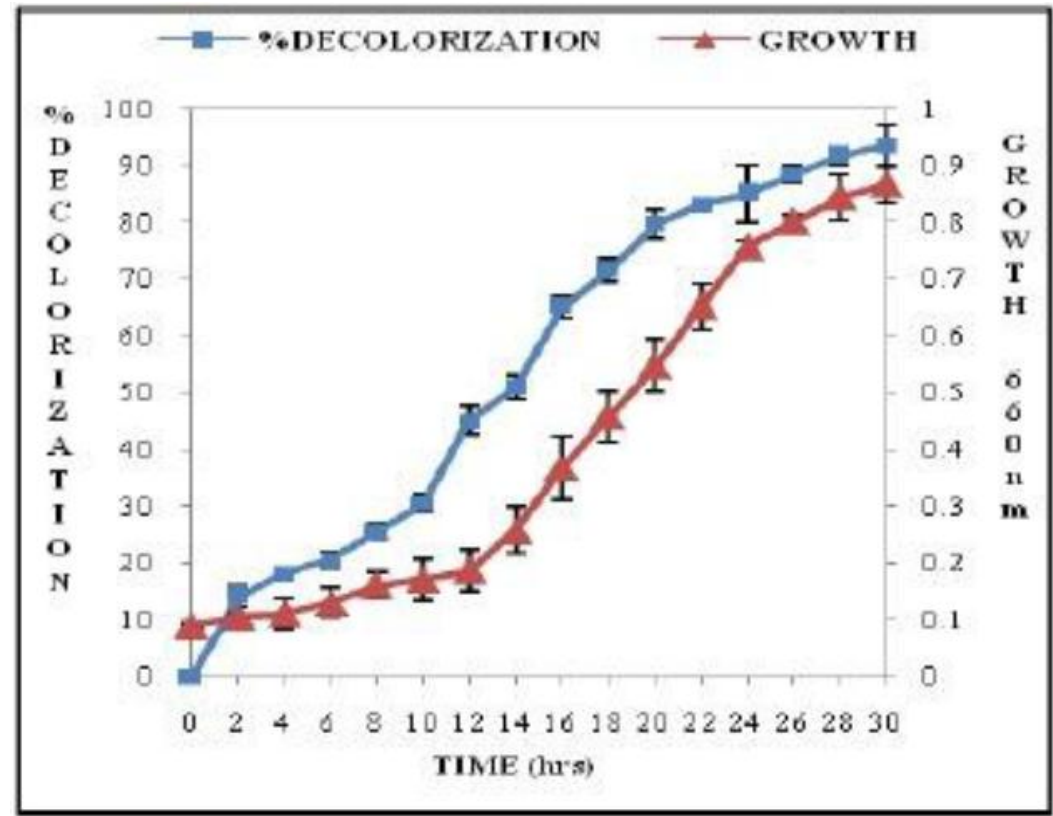

Fig 2. Decolorization of Reactive Orange M2R by Mixed Bacterial Consortium 
Microbial Degradation of Reactive Orange M2R Dye by an Application of Bacterial Consortium ETL-A: Bioremedial Approach towards Sustainable Environment

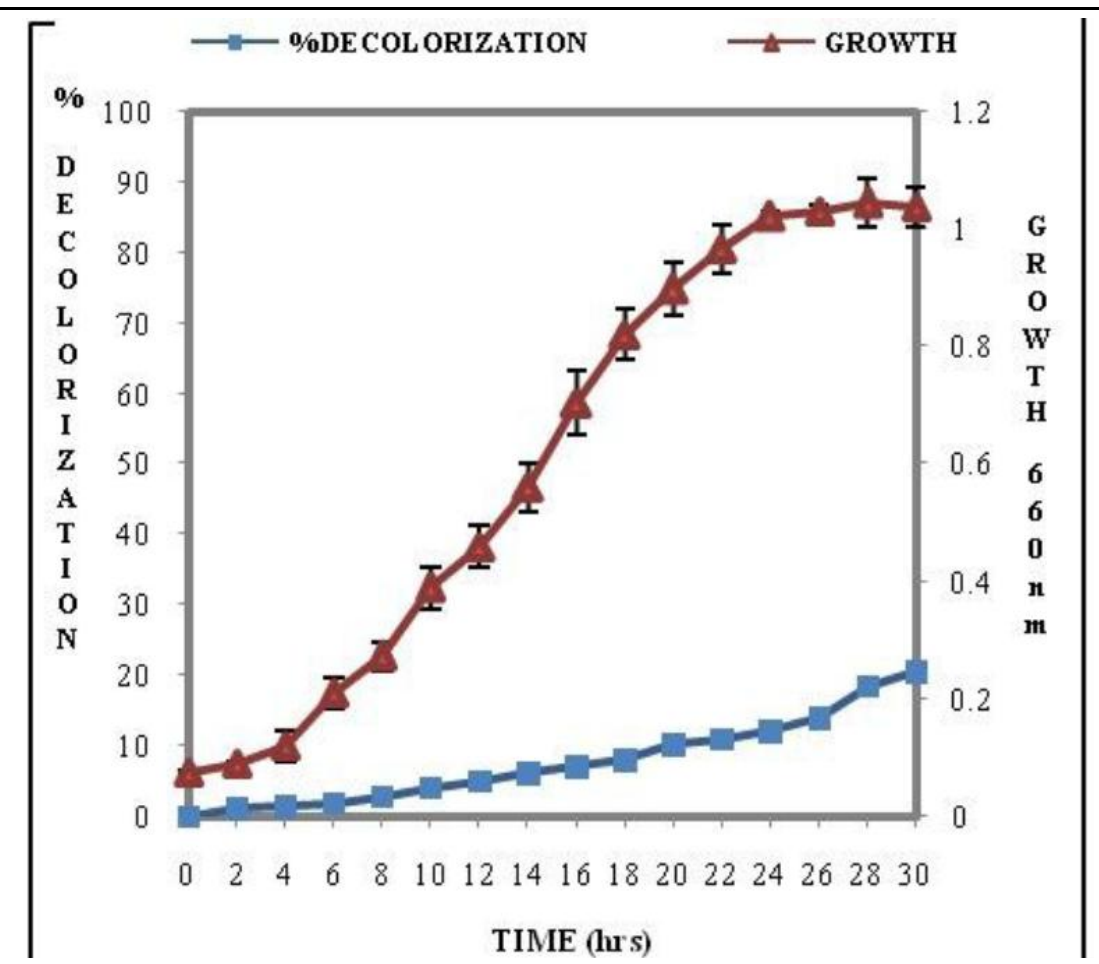

Fig 3. Decolourization of M2R by Mixed Bacterial Consortium ETL-A under Static Condition.

\section{HPTLC Analysis}

Spectrophotometric analysis at $488 \mathrm{~nm}$ of uninoculated medium (Figure 4) containing ROM2R showed a simultaneous decrease in peak of samples withdrawn at various time intervals. Evidence of the removal of dye can be observed with absorbance at $\lambda$ max being virtually zero after 48 hours of inoculation with ETL-A consortium (b) and shift of peak towards the U.V. region as shown in Figure 4. HPTLC results showed the formation of new peaks as observed and compared to control dye (Figure 5, 6, 7). The results obtained justify that the chromophoric groups were totally removed from the intact dye structure. The multiple bands obtained in the metabolite lane confirmed the biodegradation of the azo dye as compared to single band of control dye (Figure 7). The difference in Rf values (data not shown) of control dye and metabolites supports the FTIR data which suggests biodegradation of ROM2R. The similar results were reported by Chaube et al, 2010 .

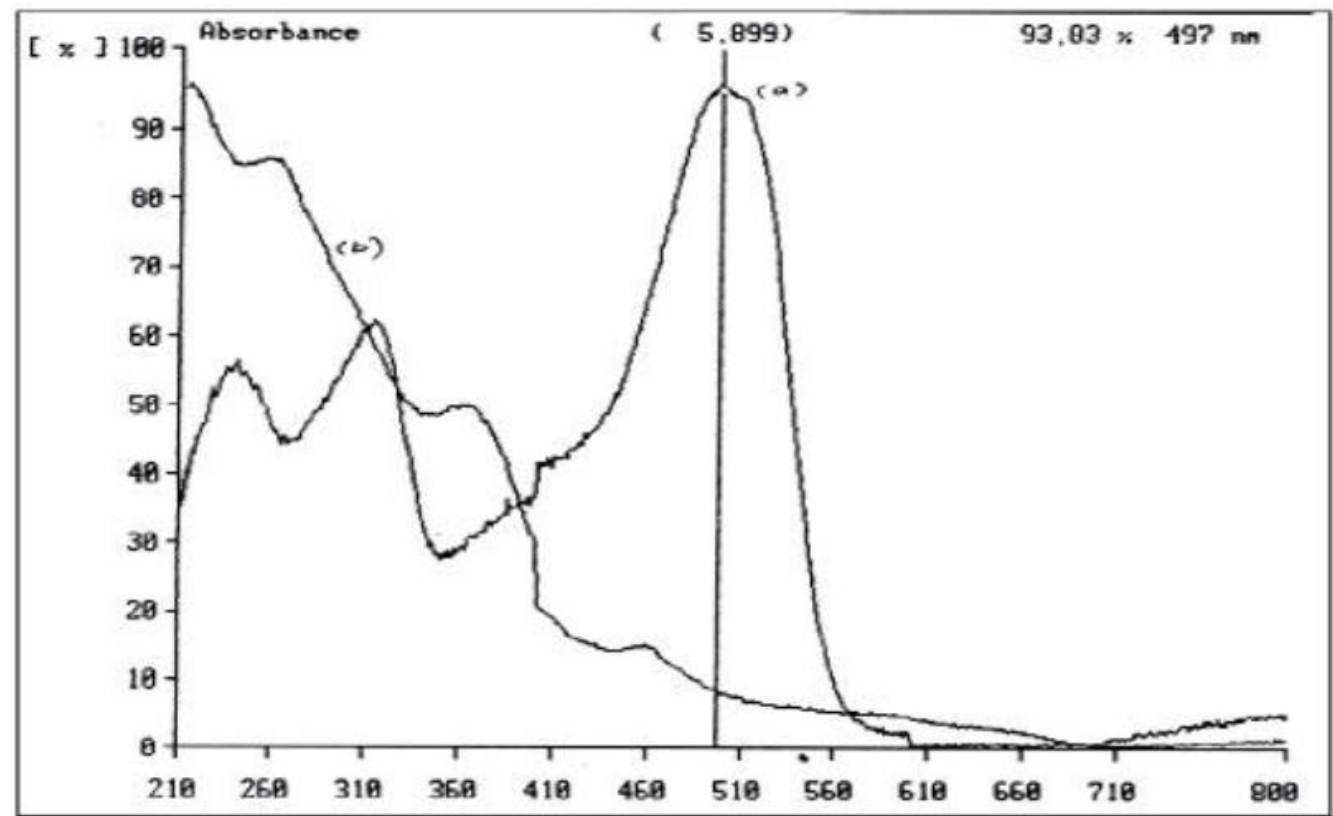

Fig 4. Spectrophotometric Analysis (a) Uninoculated media containing ROM2R (b) Media Containing ROM2R inoculated with ETL-A Consortium 


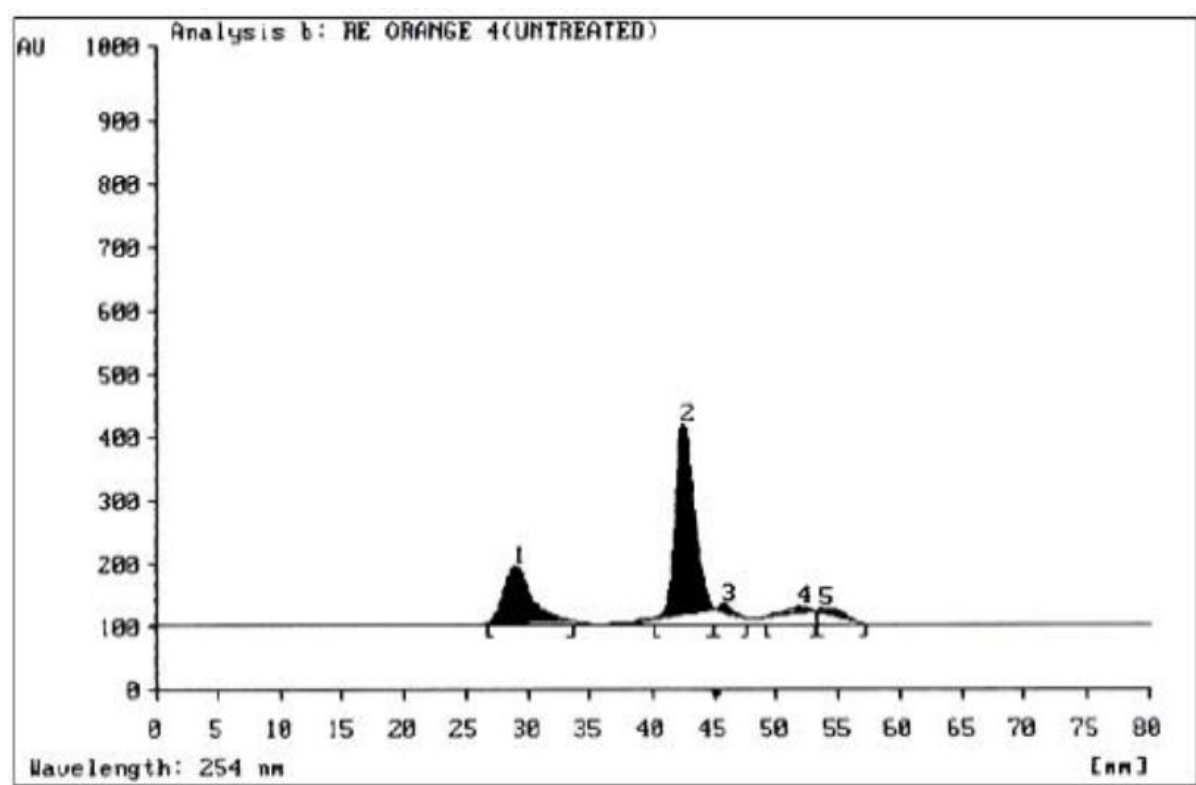

Fig 5. HPTLC Profile of ROM2R

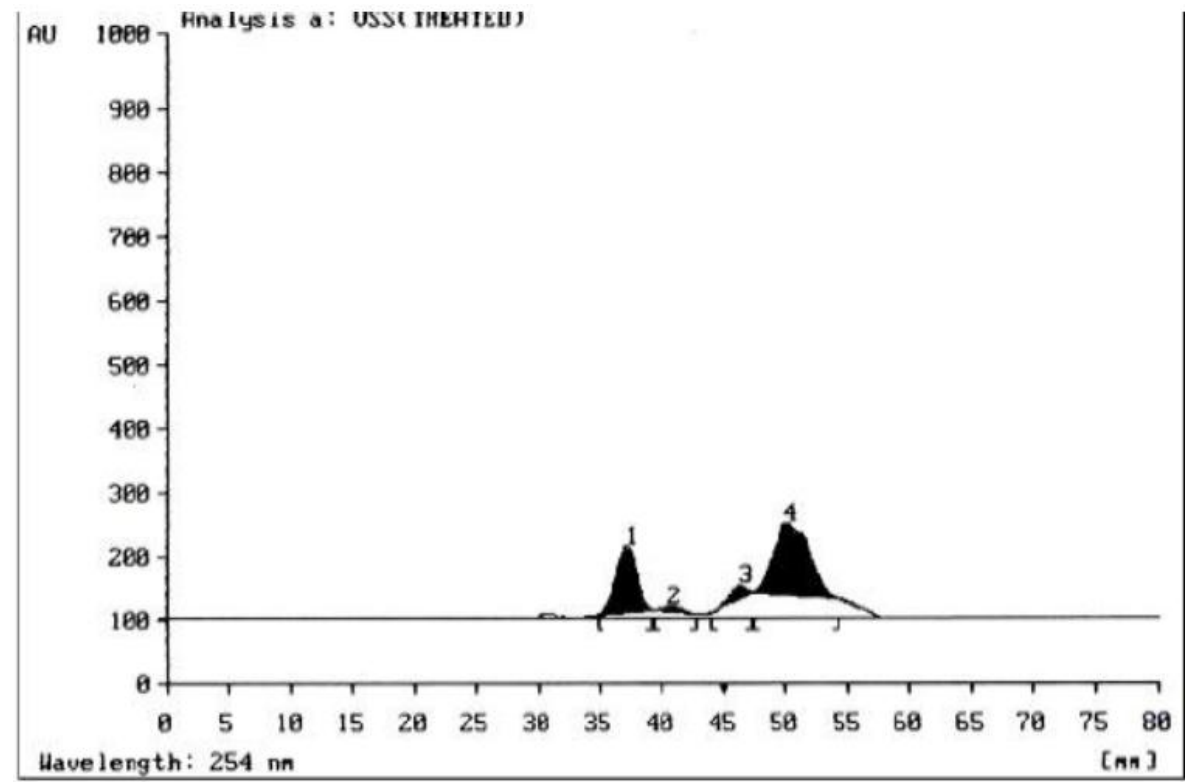

Fig 6. Metabolites of ROM2R Dye after Degradation

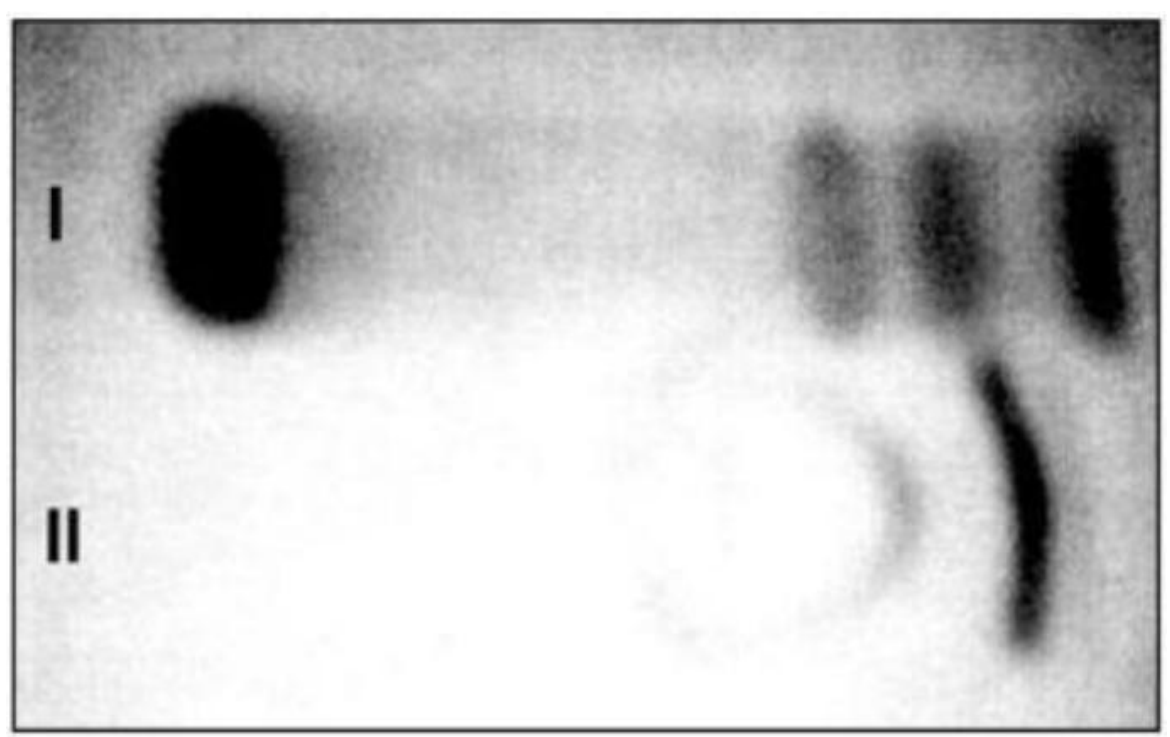

Fig 7. HPTLC Plate Exposed under UV Light, Control Dye Track(II) and Metabolites Track (I) 
Microbial Degradation of Reactive Orange M2R Dye by an Application of Bacterial Consortium ETL-A: Bioremedial Approach towards Sustainable Environment

\section{FTIR Analysis}

Results of FTIR analysis of control and sample obtained after decolorization showed various peaks (Figure 8 and 9). The FTIR spectrum of control ROM2R displays peak at $3440.1 \mathrm{~cm}-1$ for the intramolecular hydrogen bonding aromatic $-\mathrm{OH}$ and $-\mathrm{O}-\mathrm{H}$ stretching, peak at $1622.7 \mathrm{~cm}-1$ and 1555.4 $\mathrm{cm}-1$ for $-\mathrm{C}=\mathrm{C}$ stretching of aromatic rings, $1466.5 \mathrm{~cm}-1$ and $1394.6 \mathrm{~cm}-1-\mathrm{C}-\mathrm{H}$ stretching of alkyl acetals, peak at $1329.8 \mathrm{~cm}-1$ and $1187.5 \mathrm{~cm}-1$ for $-\mathrm{C}-\mathrm{N}$ stretching due to amines, peak at $845.2 \mathrm{~cm}-1$, $799.9 \mathrm{~cm}-1,763.3 \mathrm{~cm}-1$ for $-\mathrm{C}-\mathrm{H}$ stretching, $617.8 \mathrm{~cm}-1-\mathrm{C}-\mathrm{Cl}$ stretching. The degradation metabolites of ROM2R using consortium ETL-A showed peak at $3442.1 \mathrm{~cm}-1 \mathrm{for}-\mathrm{O}-\mathrm{H}-$ stretching, peak at $1644.8 \mathrm{~cm}-1-\mathrm{C}=\mathrm{C}$ stretching of alkenes, $1400.1 \mathrm{~cm}-1$ for $-\mathrm{C}-\mathrm{H}$ stretching due to $-\mathrm{CH} 3$, peak at $1110.4 \mathrm{~cm}-1,619.3 \mathrm{~cm}-1,476.9 \mathrm{~cm}-1$ for $-\mathrm{C}-\mathrm{Cl}$ stretching indicating presence of alkyl chloride. Here peak at $1392.8 \mathrm{~cm}-1$ is missing which confirms absence of amines (Figure 7) and formation of new peaks suggests the biotransformation of Reactive Orange M2R dye. The similar results were reported by Srivastava et al, 2012.

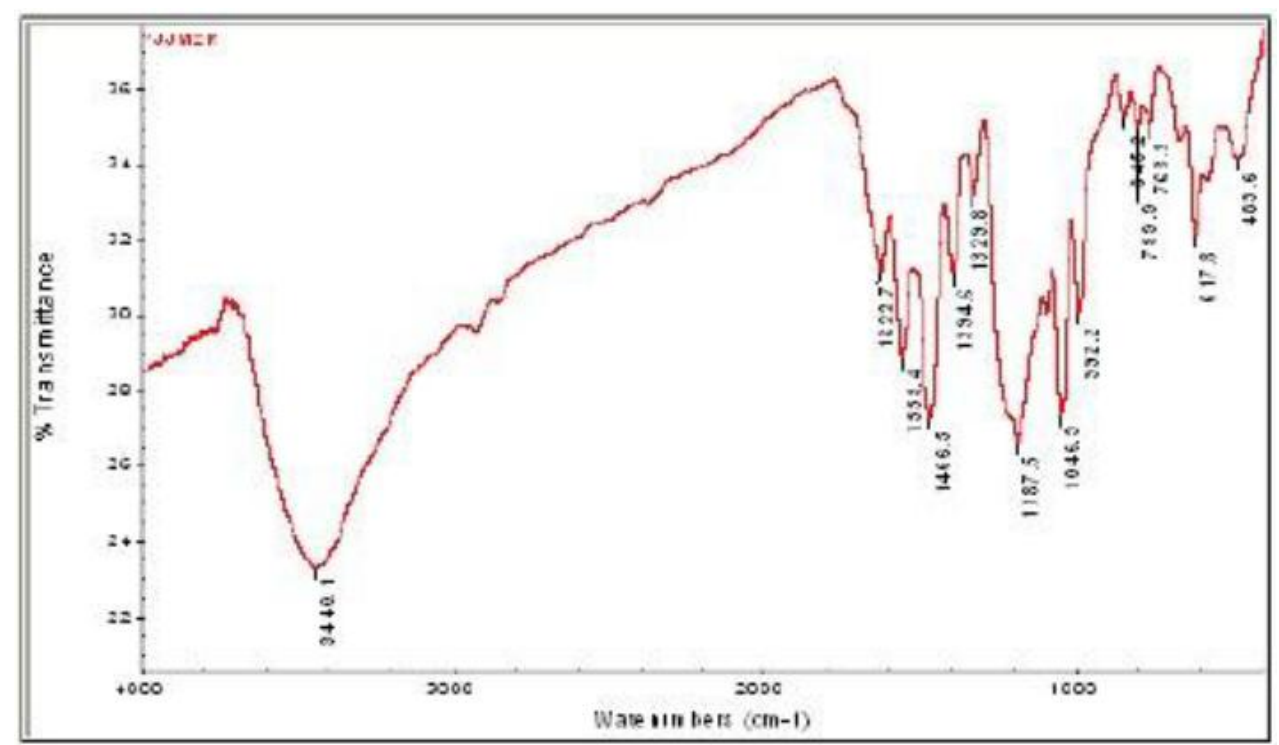

Fig 8. FTIR Spectra of Reactive Orange M2R

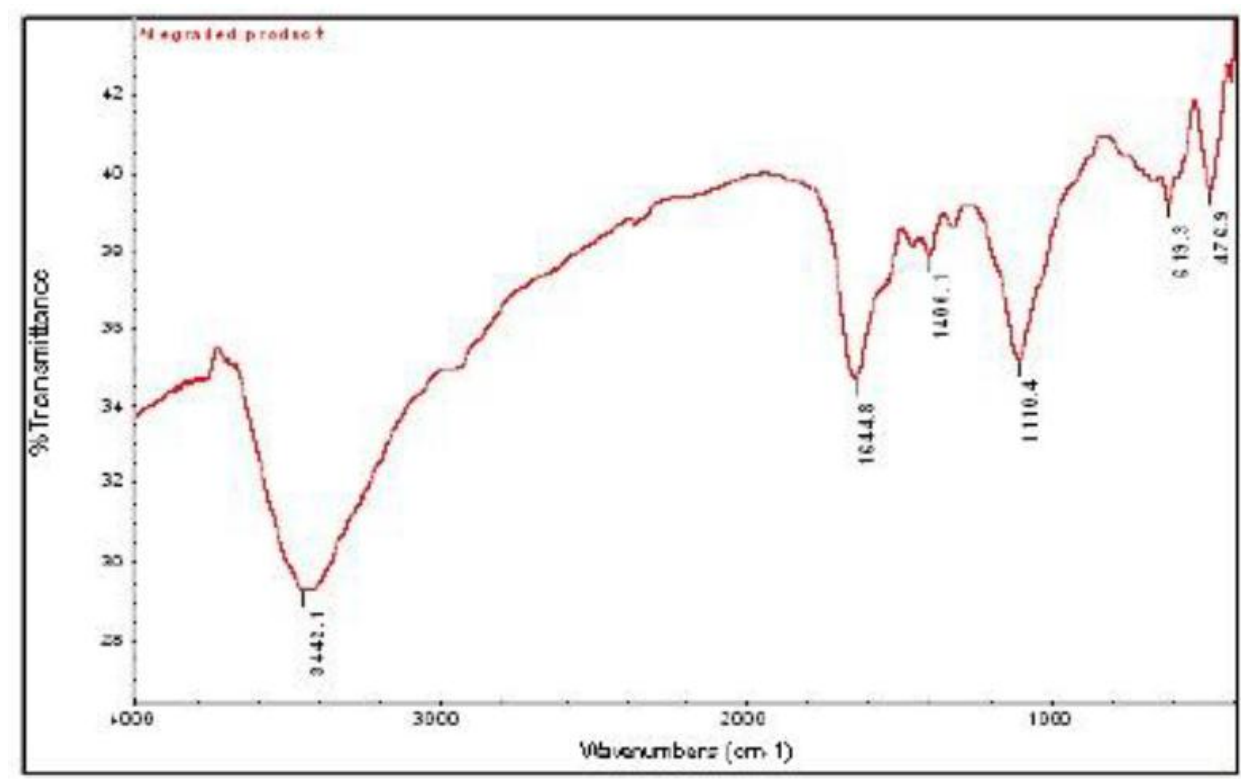

Fig 9. FTIR Spectra of Degradation Metabolites of Reactive Orange M2R

\section{Spectrum of Dyes Decolorized by the Bacterial Consortium}

Industrial effluents consist of a mixture of various dyes. Ability of consortium ETL-A to decolorize different dyes was studied (Figure 10). There was rapid degradation observed for all dyes $\left(100 \mathrm{mgl}^{-1}\right)$ used in the study within 24 hours. Reactive Orange M2R, Remazol Brilliant Red 5, Reactive Red 195, 
Red HE8B, Reactive Blue 59 showed decolorization in the range of 90-97\%. Remazol Brilliant Blue $\mathrm{R}$ and Remazol Black B showed decolorization in the range of 50-86\%. Reactive Black 8 showed decolorization in the range of $22-40 \%$. The percent decolorization varied which could be due to the structural differences of all dyes or due to the toxic effect of dyes (Khehra et al, 2005).

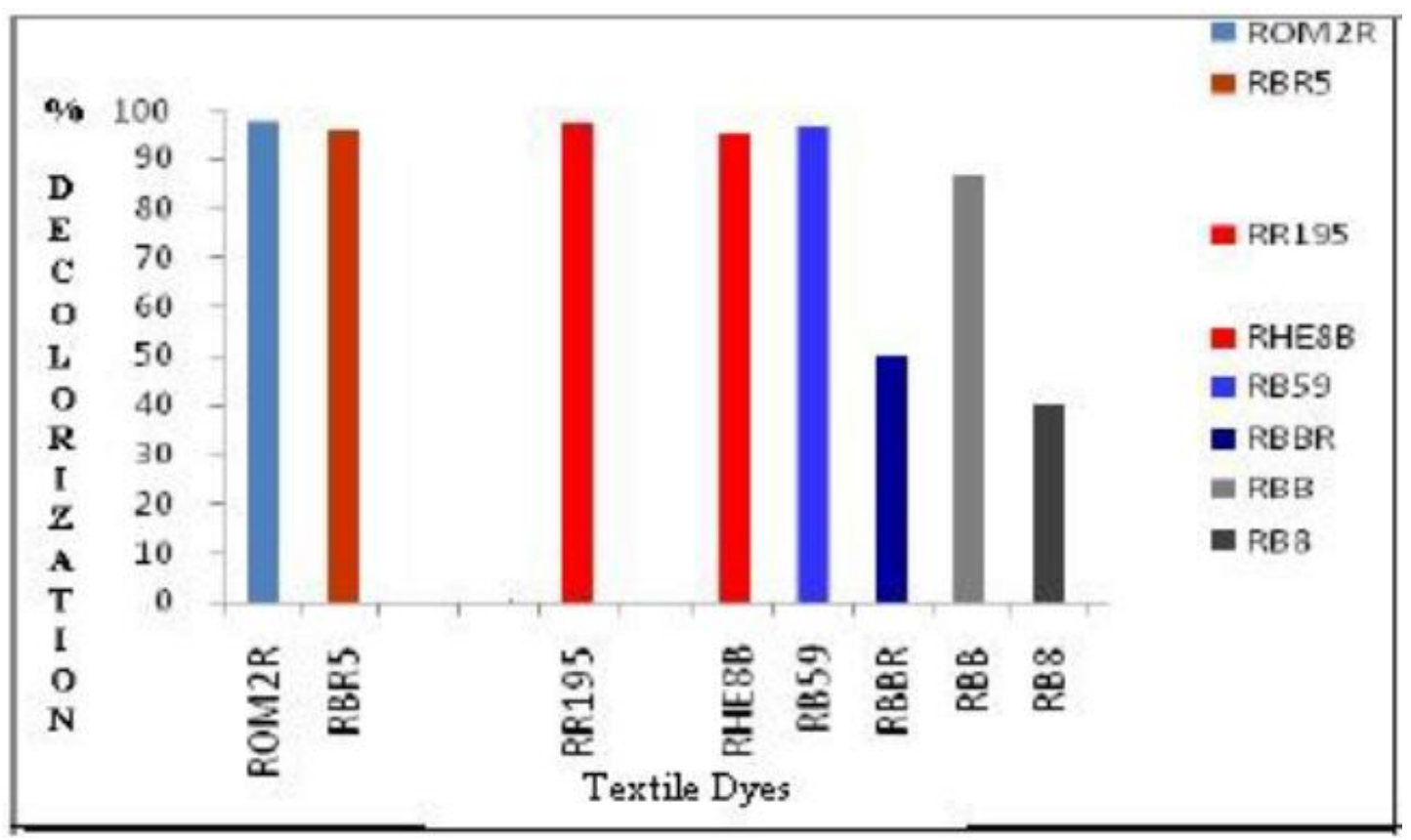

Fig 10. Spectrum of Dyes Decolorized by Consortium ETL-A

\section{Conclusion}

An extensive research study demonstrates efficient decolorization of seven out of eight dyes tested at pH 7 and $37{ }^{\circ} \mathrm{C}$ temperature by consortium ETL-A. The Consortium isolated grows best in static conditions, where in oxygen can be easily depleted, thus creating conditions favorable for decolorization of azo dyes. Reduction in COD of dye after treatment with ETL-A indicates degradation of the dye. HPTLC and FTIR results also confirm the dye degradation. High decolorization extent and complete mineralization of azo dye show the potential of this bacterial consortium to be used in the treatment of industrial effluents.

\section{REFERENCES}

[1] B. dos Santos, F. J. Cervantes, and J. B. van Lier, "Review paper on current technologies for decolourisation of textile wastewaters: perspectives for anaerobic biotechnology," Bioresource Technology, vol. 98, no. 12, pp. 2369-2385, 2007.

[2] O’Neill, F. R. Hawkes,D. L.Hawkes, N. D. Lourenc, o, H.M. Pinheiro, and W. Del'ee, "Colour in textile effluents - Sources, measurement, discharge consents and simulation: a review," Journal of Chemical Technology and Biotechnology, vol. 74, no. 11, pp. 1009-1018, 1999.

[3] Telke, D. Kalyani, J. Jadhav, and S. Govindwar, "Kinetics and mechanism of reactive red 141 degradation by a bacterial isolate Rhizobium radiobacter MTCC 8161," Acta Chimica Slovenica, vol. 55, no. 2, pp. 320-329, 2008.

[4] D. Tony, D. Goyal, and S. Khanna, "Decolorization of Direct Red 28 by mixed bacterial culture in an up-flow immobilized bioreactor," Journal of Industrial Microbiology and Biotechnology, vol. 36, no. 7, pp. 955-960, 2009.

[5] Bafana, A., Devi, S.S., Krishnamurthy, K., Chakrabarti, T., (2007). Kinetics of decolorization and biotransformation of direct black 38 by C.hominis and P.stutzeri, Applied Microbiology Biotechnology, 31, 94-97.

[6] Chang, I.S., Lin, Y.C., (2000). Fed- batch bioreactor strategies for microbial degradation of azo dye using Pseudomonas luteola strain, Biotechnol Prog, 16, 979-85.

[7] Chaube, P., Indurkar, H., Mogde, S., (2010). Biodegradation and decolorization of dye by mix consortia of bacteria and study of toxicity on Phaseolus mungo and Triticum aestivum, Asiatic $\mathbf{J}$ of Biotech Res, 1, 45-56. 
Microbial Degradation of Reactive Orange M2R Dye by an Application of Bacterial Consortium ETL-A: Bioremedial Approach towards Sustainable Environment

[8] Chen, B.Y., Chen, S.Y., Lin, M.Y., Chang, J.S., (2006).Exploring Bioaugmentation strategies for azo-dye decolorization using a mixed consortium of Pseudomonas luteola and Escherichia coli, Process Biochemistry, 41, 1574-1581.

[9] G. S. Ghodake, A. A. Talke, J. P. Jadhav, and S. P. Govindwar, "Potential of Brassica juncea in order to treat textile-effluentcontaminated sites," International Journal of Phytoremediation, vol. 11, no. 4, pp. 297-312, 2009.

[10] H. Ali, W. Ahmad, and T. Haq, "Decolorization and degradation of malachite green by Aspergillus flavus and Alternaria solani," African Journal of Biotechnology, vol. 8, no. 8, pp. 1574-1576, 2009.

[11] H. Zollinger, "Synthesis, properties and applications of organic dyes and pigments," in Color Chemistry, VCH, New York, NY, USA, 1987.

[12] Hassan, M., Hawkyard, C.J., (2002). Ferral-catalyzed ozonation of aqueous dyes in a bubble column reactor, Catal Commun, 3, 281-286.

[13] K. Singh and S. Arora, "Removal of synthetic textile dyes from wastewaters: a critical review on present treatment technologies," Critical Reviews in Environmental Science and Technology, vol. 41, pp. 807-878, 2011.

[14] Khehra, M.S., Saini, H.S., Sharma D.K., Chadha B.S., Chimmi S.S., (2005). Decolorization of various azo dyes by bacterial consortium, Dyes Pigments, 67, 55-61.

[15] M. Gou, Y. Qu, J. Zhou, F. Ma, and L. Tan, "Azo dye decolorization by a new fungal isolate, Penicillium sp. QQ and fungal-bacterial cocultures," Journal of Hazardous Materials, vol. 170, no. 1, pp. 314-319, 2009.

[16] N. Daneshvar, M. Ayazloo, A. R. Khataee, and M. Pourhassan, "Biological decolorization of dye solution containing Malachite Green by microalgae Cosmarium sp," Bioresource Technology, vol. 98, no. 6, pp. 1176-1182, 2007.

[17] Nigam, P., Banat, I.M., Marchant, R., (1996). Decolorization of effluent from the textile industry by a microbial consortium, Biotech Lett, 18, 117-120.

[18] Patil, P.S., Phugare, S.S., Jadhav, S.B., Jadhav, J.P., (2010). Communal action of microbial cultures for RED HE3B degradation, Journal of Hazardous Materials, 181, 263-270.

[19] Phugare, S.S., Kalyani, D.C., Patil, A.V., Jadhav, J.P., (2011). Textile dye degradation by bacterial consortium and subsequent toxicological analysis of dye and dye metabolites using cytotoxicity, geneotoxicity and oxidative stress studies, Journal of Hazardous Materials, 186, 713-723.

[20] S. R. Couto, "Dye removal by immobilised fungi," Biotechnology Advances, vol. 27, no. 3, pp. 227-235, 2009.

[21] S. W. Won, S. B. Choi, and Y. S. Yun, "Interaction between protonated waste biomass of Corynebacterium glutamicum and anionic dye Reactive Red 4," Colloids and Surfaces A, vol. 262, no. 1-3, pp. 175-180, 2005.

[22] Srivastava, S.K., Tripathi, A., (2012). Biodegradation of orange G by a novel isolated bacterial strain B.megaterium ITBHU01 using response surface methodology, African J of Biotechnol, 11(7), 1768-1781.

[23] T. Robinson, G. McMullan, R. Marchant, and P. Nigam, "Remediation of dyes in textile effluent: a critical review on current treatment technologies with a proposed alternative," Bioresource Technology, vol. 77, no. 3, pp. 247-255, 2001.

[24] V. K. Gupta and A. Rastogi, "Biosorption of hexavalent chromium by raw and acid-treated green alga Oedogonium hatei from aqueous solutions," Journal of HazardousMaterials, vol. 163, no. 1, pp. 396-402, 2009.

[25] V. K. Gupta and A. Rastogi, "Biosorption of lead from aqueous solutions by green algae Spirogyra species: kinetics and equilibrium studies," Journal of Hazardous Materials, vol. 152, no. 1, pp. 407-414, 2008.

[26] V. K. Gupta, A.Mittal, L. Krishnan, and V. Gajbe, "Adsorption kinetics and column operations for the removal and recovery of malachite green from wastewater using bottom ash," Separation and Purification Technology, vol. 40, no. 1, pp. 87- 96, 2004. 
[27] W. Zhou and W. Zimmermann, "Decolorization of industrial effluents containing reactive dyes by actinomycetes," FEMS Microbiology Letters, vol. 107, no. 2-3, pp. 157-161, 1993.

[28] Y. Ji, X. T. Li, and G. Q. Chen, "Interactions between a poly(3-hydroxybutyrate-co-3hydroxyvalerate-co-3-hydroxyhexanoate) terpolyester and human keratinocytes," Biomaterials, vol. 29, no. 28, pp. 3807-3814, 2008.

[29] Yang, Q., Li, C., Li, H., Li, Y., Yu, N., (2009). Degradation of synthetic reactive azo dyes and treatment of textile wastewater by a fungi consortium reactor, Biochemical Engineering Journal, $43,225-230$. 